\title{
VIDAS DIGITALES: \\ Comunicación y cultura de la participación en red
}

Carlos DIZ; Arturo DE NIEVES

Universidade da Coruña

carlos.diz@udc.es, arturo.denieves@udc.es

DIGITAL LIVES: Communication and culture of network participation

Resumen: Analizaremos en este artículo las vidas digitales de los jóvenes occidentales conectados a internet. Prestaremos especial atención al papel de la comunicación y las nuevas tecnologías de la información en la sociedad contemporánea y en el ámbito juvenil, así como a su reapropiación tecnopolítica por parte de estos jóvenes en el contexto de los movimientos sociales en red: primaveras árabes, 15M, \#YoSoy132... Pensaremos las vidas digitales desde el punto de vista de la participación ciudadana y describiremos una cultura de la participación en red forjada entre las calles y las redes sociales, donde la comunicación es el primer recurso y a menudo el más disputado.

Abstract: We will analyze in this paper the digital lives of young Westerners connected to the internet. We will pay attention to the role of communication and new information technologies in contemporary society and particularly in the youth field, as well as to the techno-political reappropriation by these young people in the context of networked social movements: Arab springs, 15M, \#YoSoy132... We will think about digital lives from the point of view of citizen participation and we will describe a culture of network participation forged between streets and social networks, where communication is the first and very often the most contested resource.

Palabras clave: Comunicación De Masas. Medios Sociales. Movimiento Social. Participación Juvenil Mass Communication. Social Media. Social Movements. Youth Participation 


\section{Introducción}

Escribimos este texto a cuatro manos y desde distintos lugares. Lo hacemos viajar a través del tiempo y del espacio, en diferentes husos horarios, circulando entre el sur de Europa y el África oriental. Sus revisiones y actualizaciones son enviadas en cualquier momento a través del correo electrónico, y sus comentarios se desarrollan en mensajes de Facebook, chats y notas de voz de WhatsApp o videoconferencias en Skype. Para cuando hayamos concluido este artículo habremos paseado nuestros dedos y nuestra mirada por múltiples pantallas, y nos habremos servido de varios dispositivos tecnológicos: tablets, smartphones, ordenadores portátiles, etc. Porque escribir un texto es dar luz al contexto que lo produce, y así hemos de comenzar reconociendo, en esta era de información globalizada, este ensamblaje plural e interconectado de espacios, artefactos, tecnologías y temporalidades que escriben y se inscriben en el texto. Si pretendemos hablar aquí de vidas digitales, empezaremos señalando que nuestras vidas -enredadas vía internet- son también unas "vidas conectadas" (Serrano-Puche, 2013).

En este artículo trataremos de analizar las vidas digitales, esto es, la vida social de los jóvenes conectados y atravesados hoy por la cultura digital contemporánea. Una cultura que produce en su despliegue nuevos ritmos y lenguajes, que potencia la aparición de otros actores y escenarios, y que halla en la comunicación y en la tecnología su marco de acción y su razón de ser. Más concretamente, nos interrogaremos por el uso y el papel de internet en la participación ciudadana, sabiendo que en un contexto global y sociotécnico la comunicación se ha convertido en un campo de poder y conflicto, un campo de batalla político y cultural. En este sentido, comentando algunos de los recientes movimientos sociales surgidos en el norte de África, Europa y Latinoamérica, prestaremos especial atención a la "tecnopolítica", entendida aquí como el uso táctico de las herramientas digitales para la organización, comunicación y acción colectivas (Jurado Gilabert, 2014). En muchos de estos casos, el manejo previo que estos jóvenes hacían de la Web 2.0 prefiguraba las protestas callejeras, allí donde se materializaba una cultura de la participación en red que era, a menudo, el reflejo de una cultura de la participación en la red, más o menos eficiente. Sin embargo, antes de proseguir, arranquemos con una anécdota de la actualidad política española que durante semanas reclamó la atención tanto del gobierno como de las redes sociales y los mass media.

\section{Conectando: metáforas, nervios y brechas}

Septiembre de 2017. Uno de nosotros se levanta a primera hora y se prepara para una jornada de trabajo desde casa. Vive esta temporada con sus padres en una vivienda de dos plantas. Desayuna y se activa. Vuelve a su habitación. La mañana es fresca. Cierra la ventana que aireaba la pieza, ordena su escritorio y enciende su teléfono móvil y su ordenador. Se conecta a Facebook y a WhatsApp, vinculando entre sí su smartphone y su computadora. Abre y cierra ventanas a medida que consulta las últimas noticias en la prensa digital, guardando en el escritorio de su portátil varios artículos que -si tiene tiempo- leerá después. Entonces recuerda, al abrirse el día, cómo la comunicación mediada por ordenadores se estructura en torno a una metáfora espacial (ventanas, escritorios, galerías), como si la acción social -ya se produzca en la calle o en internet- solo pueda darse a través de espacios (Mayans i Planells, 2012). Así, junto a las metáforas cotidianas que dan sentido a lo que nos rodea, que ordenan nuestras vidas y embeben el habla y el pensamiento y la acción (Lakoff y Johnson, 1998), las nuevas metáforas computacionales sirven también para orientar nuestras vidas digitales, sabiendo quién está "desconectado" o "conectado" a la red, qué se "sube" o se "baja" de la nube, quién está "dentro" o "fuera" de la conversación, quién está o no está on line...

$\mathrm{Al}$ cabo de un rato todo se alumbra y se acelera. Bip. Bip. Clic. Clic. Suenan alertas del Messenger y de los grupos de WhatsApp. Los muros de Facebook se llenan de mensajes: muchos se comparten o se replican, otros directamente se transportan o se copian desde Twitter. Aceleración, nerviosismo, excitación e instantaneidad, patrones contemporáneos de la comunicación digital. ¿El contexto? La escalada de tensión entre el Gobierno de España y el Govern de Catalunya no ha hecho sino ir a más en los últimos meses. Finalmente, la convocatoria de un referéndum por la independencia catalana el 1 de octubre de 2017, considerado ilegal por el gobierno español, ha agitado aún más el Congreso y el ciberespacio. Ante la falta de negociación política, el Estado ha optado por enviar miles de agentes de la Guardia Civil y la Policía Nacional al territorio catalán, con el objeto de impedir el referéndum. Tal es el contingente que el Ministerio del Interior ha decidido que una parte de esos agentes atraque y se aloje temporalmente en el puerto de Barcelona, a bordo del crucero Moby Dada.

Lo que ya de por sí resulta una decisión curiosa y a la vez polémica, pues buena parte de la sociedad catalana y española aboga por el diálogo y no por la intervención policial, acoge ahora un tinte surrealista dadas las características del buque en cuestión. En sus costados y a todo color, el navío arriba decorado con 
el Coyote, el Pato Lucas, Piolín, Silvestre y el demonio de Tasmania, los famosísimos dibujos animados de Looney Tunes, de la compañía Warner Bros. Las redes estallan de risa. Las bromas, los chistes y los memes circulan sin piedad y a toda velocidad, ayudando en parte (y solo a algunos) a aliviar una situación más bien dramática. En este contexto, el humor actúa y se instrumentaliza como una táctica de comunicación, un lenguaje y una estética singular cuyos usos políticos y sociales por parte del activismo ya han sido tratados en otro lugar (Diz, 2016b). Gente anónima y políticos de primera línea, activistas favorables o no a la independencia, comparten textos e imágenes que reflejan una situación que es vista como ridícula y que, una vez viralizadas, se cuelan durante días en cualquier conversación, en soportes y formatos varios: periódicos, tele, radio, internet, bares...

De pronto, Piolín se erige en un símbolo del movimiento pro-referéndum [Figura 1]. Como todo símbolo, y como toda comunicación on line, tiene un punto de ambigüedad. Para unos, atracado en el barco de la policía, Piolín simboliza una fuerza represora y españolista, y durante días se habla de los antidisturbios como "piolines"; para otros, se convierte en símbolo de la resistencia y del derecho a decidir, y en los días sucesivos las manifestaciones catalanas se llenan de caretas, camisetas, pancartas, globos y disfraces de Piolín, pasando así de la protesta en la red a la protesta en las calles. En unas horas, la mañana se incendia con información que circula a raudales por la red, pasando de las redes sociales a la prensa digital que se actualiza paulatinamente, del Twitter al Facebook, de allí al WhatsApp, y así sucesivamente. También la clase política se hace eco. Gabriel Rufián, joven portavoz de Esquerra Republicana de Catalunya (ERC) en el Congreso, muy activo en Twitter y cuyo grupo parlamentario reclama el derecho de autodeterminación, publica un meme con la siguiente frase: "Eso es to, eso es to, eso es todo España" [Figura 2]. Junto a la imagen del crucero Moby Dada, esta expresión hace referencia a la mundialmente conocida That's all Folks!, con la que se despedía el cerdito Porky en cada fin de emisión de los Looney Tunes. Indudablemente, tomando el desembarco policial como punto de inflexión sin vuelta atrás, el joven político ironizaba sobre la situación al tiempo que se despedía de España y alentaba la independencia.

Figura 1

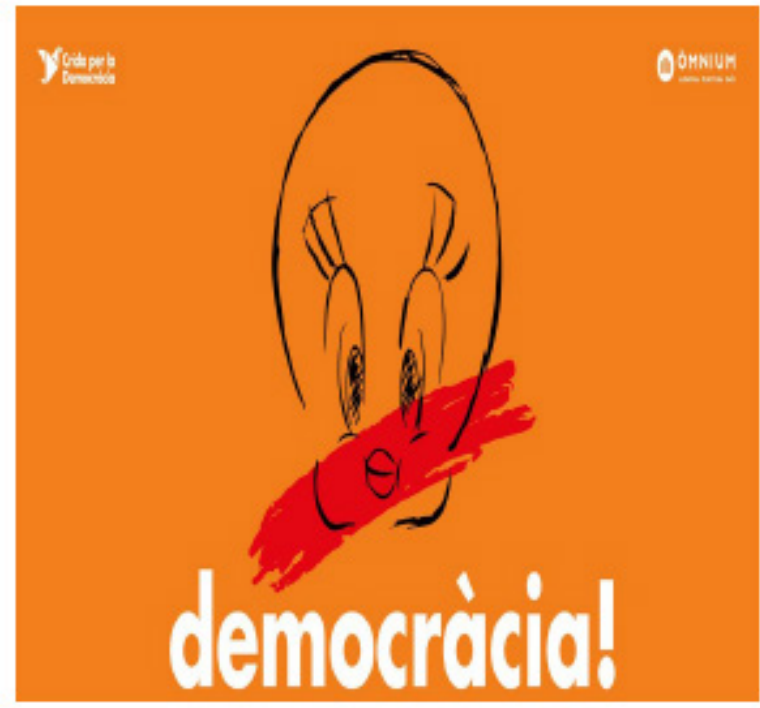

Fuente: Òmnium Cultural.
Figura 2

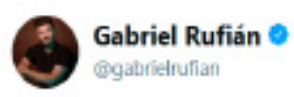

Eso es to, eso es to, eso es todo España.

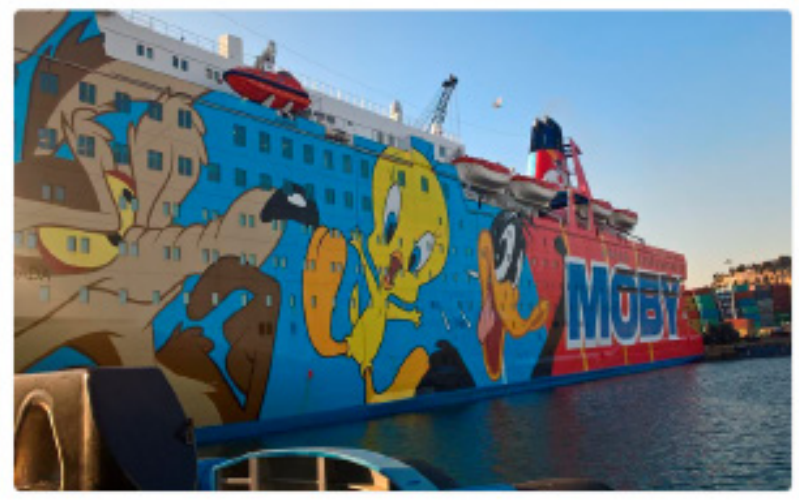

14:32- 21 sept 2017

Fuente: Twitter.

Su publicación en la web sería retwittetada, compartida en otras redes, comentada, replicada y transformada. Así funcionan los memes de internet, unidades de información que pueden manifestarse textual o audiovisualmente en cualquier medio virtual, que alcanzan una amplia difusión o "contagio" por su carácter satírico o llamativo, que pueden mantenerse inmutables o evolucionar con el tiempo. Imágenes que suelen recuperar elementos de la cultura popular y de masas (fotos, dibujos, películas, videojuegos, series de televisión, etc.), y que se emplean para vehicular ideas, situaciones o pensamientos. Son juegos, al fin y al cabo, que se juegan a través del reciclaje y la remezcla o remix, sin autoría o de autoría múltiple (Lessig, 2012), y que -como en este caso- nos dan una idea de la importancia de los contenidos gráficos en la conversación política 2.0, a la vez que son el vivo ejemplo de una apropiación y resemantización constante, creativa e ingeniosa de los contenidos culturales (García-Huerta, 2014; Martínez Rolán y Piñeiro-Otero, 2017). 
Abrumado por tanta información, consumida ya la mañana, quien ahora escribe cierra su sesión y baja a comer. En la planta baja de su casa comparte la comida con sus padres. La televisión, encendida, escupe un parte informativo que se alimenta por momentos del runrún de imágenes, textos e incluso bromas que su hijo -horas antes y en su computadora- ha descubierto y comentado en la red. Ciertos canales recuperan y se hacen eco de las imágenes de Piolín, llegando a comentar los tweets más viralizados. En tal contexto, pasar de la habitación a la cocina, bajar las escaleras, supone cruzar un umbral espaciotemporal. En la comida compartida, frente al televisor, se hace evidente y se materializa una brecha generacional, una distancia que es a la vez temporal, tecnológica y comunicacional. Una brecha digital que nos habla de las asimetrías contemporáneas -no solo geográficas y geopolíticas sino también etarias, etc.- en la producción, circulación y consumo de noticias. Para sus padres, la televisión y la prensa en papel siguen siendo fuentes de información primordiales. Y si prosiguiésemos con la metáfora, además, cada piso de la casa traería consigo sus consiguientes distanciamientos. Nosotros, si se quiere, nacidos a mediados de los 80, ocuparíamos un piso intermedio -siguiendo la conceptualización de Feixa (2014)- entre la "Generación X" y la "Generación@”, jóvenes ya socializados en la era de internet, pero estaríamos por debajo de la "Generación\#”, que llega a la juventud en plena crisis financiera global (2008), con una cultura "glocal", un tiempo "viral" y un contexto "hiperdigital".

En cualquier caso, el ejemplo anterior nos da una pista de la obsolescencia, o mejor, de la convivencia de nuevos esquemas con el viejo esquema emisor-mensaje-receptor. Hoy operan multitud de emisores que son al mismo tiempo receptores, que producen y reproducen mensajes por múltiples canales. En España, como en tantos lugares, sobre todo con el estallido de la crisis financiera y la aparición de movimientos sociales como el 15M en 2011, "el ciberactivismo ha desarrollado una metodología de comunicación masiva en redes sociales, principalmente Twitter y Facebook, que tiene, como uno de sus objetivos, la penetración en los índices de noticias de los medios de comunicación de masas" (Jurado Gilabert, 2014: 75). Así, en Twitter por ejemplo, hay noticias o "temas" (Topics) que se convierten en tema central de discusión. Una vez que se comparten y difunden a escala masiva -local, nacional o internacionalmente- se vuelven "tendencia" (Trending Topics), y pueden ser utilizados por los medios mainstream como un indicador de lo que comenta la ciudadanía en esos momentos. Es decir que, por un lado, ciertos usuarios de la web no son meros receptores sino que se convierten en emisores y productores que editan y distribuyen contenidos; y por otro lado, este nuevo "ecosistema mediático" modifica no solo el proceso de producción de la información sino también los criterios de noticiabilidad (Tascón y Quintana, 2012).

En este artículo pensaremos las vidas digitales desde el punto de vista de la participación en red. Metodológicamente, usaremos la revisión bibliográfica y nos serviremos de los resultados del trabajo de campo profundizado en otro lugar (Diz, 2016, 2016b). Primero estableceremos el marco teórico que cruza entre sí la comunicación, la participación y las nuevas tecnologías de la información. A continuación analizaremos el uso y la reapropiación que de estas tecnologías han hecho los recientes movimientos sociales, de las "primaveras árabes" norteafricanas al 15M español, del \#yosoy132 mexicano al Passe Livre brasileño. Por último, trataremos de comprender estas vidas digitales a través de una cultura de la participación en (la) red, una cultura híbrida, compleja e hiperconectada que convierte la comunicación en un valor primordial.

\section{Actualizando: comunicación y tecnologías en la era de la información}

Es evidente, desafiando cierta mística del progreso, que toda sociedad ha sido siempre una sociedad del conocimiento y de la información, presentes en formas y grados variables; cazadores y recolectores debían informarse sobre su entorno y adquirir conceptos, técnicas y saberes para salir adelante. Lo que es cierto es que hoy, y al menos desde los años 70, las nuevas tecnologías provocan que la generación, procesamiento y transmisión de información y conocimiento se conviertan en la principal fuente de producción de poder y riqueza (Castells, 2003). En la era de internet y las redes sociales, en que las protestas juveniles y callejeras se inspiran -como lo hizo con anterioridad, por ejemplo, el llamado movimiento global o movimiento antiglobalización- en la arquitectura y en las dinámicas de la red (Klein, 2001; Juris, 2008), conviene recordar que fue la circulación y la aceleración del capitalismo moderno la que se adelantó a la velocidad e hiperactividad de la web. Aquellas calles de las ciudades modernas que veían incrementarse de pronto la vida nerviosa como consecuencia de un intercambio fugaz y constante de impresiones interiores y exteriores (Sennett, 1997; Simmel, 2002), hallan hoy su traducción virtual en la circulación masiva de mensajes en el ciberespacio, en el marco de una globalización asimétrica en que vemos moverse incesantemente informaciones, datos, objetos, imágenes, tecnologías, tendencias y productos culturales (Appadurai, 2002; Warnier, 2002; Urry, 2007).

Cuando hablamos de vidas digitales lo hacemos ante todo para subrayar su carácter eminentemente social. En este sentido, cabe indicar que entendemos la virtualización como una dinámica, que no implica la desrealización sino una mutación de la identidad (Lévy, 1999). Por ello, las vidas digitales no son sino vidas 
conectadas, en proceso y transformación; vidas atravesadas por una progresiva digitalización de la realidad física y del mundo social, lo que implica la paulatina reducción de los contenidos a una masa de bits (Scolari, 2012). Es decir, lo virtual, lo digital, no son campos independientes ni esferas separadas de lo real sino que componen y recomponen la realidad misma, la reimaginan y la reinterpretan, la reactualizan. "Internet es un laboratorio del mundo real y también su réplica, mejorada o empeorada. Es, sobre todo, un testeo acelerado de relaciones y prácticas sociales" (Piscitelli, 2009: 45). Relaciones que mutan on line, como ocurre en Facebook, la red social nacida en 2004 y que cuenta ya con más de 1.500 millones de usuarios en todo el mundo, un sitio en que usar -irremediablemente- supone comunicar, y donde lo real se redefine, por ejemplo, a través de otra ontología de la amistad (¿qué es un "amigo" en Facebook?) o con otra ontología de la temporalidad, cuyo timeline nos aboca a un presente continuo, excitado y perpetuo.

Relaciones y prácticas, decimos, que hallan en el ciberespacio un lugar capital de enunciación y sociabilidad, un lugar donde expresar la identidad a través de la técnica y la tecnología. Un espacio practicado, un terreno híbrido donde interactúan humanos y máquinas digitales, donde los contenidos son maleables y los vínculos sociales flexibles, lo que permite "un tráfico de sociabilidades y juegos identitarios fluido, líquido, liberado de muchas de las barreras físicas que la distancia o el cuerpo han impuesto, tradicionalmente, sobre la sociabilidad humana" (Mayans i Planells, 2012: 241). Pero un tráfico, al fin y al cabo, igualmente sujeto a límites y señalizaciones, enmarcado y regulado por un conjunto de normas, juegos y movimientos comunicacionales y de (re)presentación; qué duda cabe, en tal contexto de exhibición y de pública exposición del "yo", que la "gestión de las impresiones" referida por Goffman (1987) se antoja esencial, también en el ciberespacio, para la presentación de la persona en la vida cotidiana on line, donde toda actuación es una actualización.

En este punto, hablando de cultura digital, queremos indicar cómo la introducción de nuevas tecnologías comporta siempre una renegociación del tiempo, el espacio y el lenguaje, una reconceptualización del mundo. Así como el telégrafo suprimió la necesidad del espacio para mover la información, desvinculando transporte y comunicación; así como la prensa alteró lo que entendíamos por información; o así como la televisión modificó la idea de las noticias y de la opinión pública, siendo además la antítesis del nomadismo y de los dispositivos móviles al introducir en el hogar estrategias de la sociedad industrial y disciplinaria, fijando a los individuos en un lugar, separándolos entre sí y restándoles con ello conciencia y efectividad política (Crary, 2012); así, también, las nuevas tecnologías de la información nos hacen hablar de otro modo -como en las metáforas computacionales ya indicadas al inicio-, nos emplazan a habitar el ciberespacio y redefinen los conceptos de comunicación, participación, saber o verdad. Por ello, las tecnologías han de aprehenderse en su complejidad, sabiendo que no conllevan efectos unilaterales sino múltiples, en todas direcciones y a menudo imprevistos -como el propio uso de Internet, inicialmente orientado a su aplicación militar-, y están preñadas de intención e ideología:

Las nuevas tecnologías alteran la estructura de nuestros intereses: las cosas sobre las que pensamos. Alteran el carácter de nuestros símbolos: las cosas con las que pensamos. Y alteran la naturaleza de la comunidad: el espacio en que se desarrollan los pensamientos. (Postman, 1994: 33)

Sin embargo cabe ser precavidos, desconfiar del determinismo tecnológico y atender a los juegos de reapropiación tecnosocial y tecnopolítica (Diz, 2016b), siendo un ejemplo -como veremos a continuaciónlos movimientos en red. Quién habría imaginado, por ejemplo, que el reloj mecánico, diseñado en los monasterios benedictinos en los siglos XII y XIII para ayudar a las campanas a marcar las horas canónicas e indicar con precisión el tiempo del rezo, sería erigido siglos más tarde en emblema del capitalismo, esencial para controlar y sincronizar los movimientos de los trabajadores y para regularizar la producción (Thompson, 1979; Postman, 1994). Del mismo modo, las nuevas tecnologías de la información -las de la Web 2.0, entre otras- acogen múltiples usos y significados, a menudo no previstos en su diseño original, y destinados -como ha ocurrido con toda tecnología- a ser objeto de críticas tanto "tecno-optimistas", alabando la interconexión mundial, el sentido de comunión, la creatividad, la cultura participativa, la democratización comunicativa o la inteligencia colectiva (Lévy, 2004; Jenkins, 2008; McLuhan 2010), como "tecno-pesimistas", abrumadas por una nebulosa virtual hiper-acelerada, que conecta a unos pero desconecta a otros, y que se nutre de un circuito frío y escalofriante de individualismo, competitividad, soledad, depresión, apatía y banalidad (Postman, 1994; Slouka, 1996; Virilio, 1997).

Así, las narrativas de futuro y esperanzamiento que han acompañado históricamente a las tecnologías, del telégrafo a los blogs (Estalella, 2012), conviven hoy con discursos que nos muestran una cara ni tan amable ni tan lisa. El mundo cibernético, para algunos una promesa de utopía, "ciberdemocracia" y "diálogo político" (Lévy, 2004), no es ajeno a conflictos, relaciones de poder o sofisticadas estrategias de control, marketing y vigilancia. Véase el caso de la comunicación en Facebook. El mito del intercambio abierto, libre y plural se ve hoy amenazado por el llamado "filtro burbuja", el ecosistema personal de información creado y recreado sistemáticamente por algoritmos (Pariser, 2017). Tal filtro aparece como resultado de 
nuestras búsquedas personales, donde el algoritmo de una web concreta selecciona -en base a predicciones- la información que cree que nos gustará ver, guiándose por el rastro que hemos dejado hasta entonces en internet (historial de búsquedas, frecuencia de clics, geolocalización, etc.). Al final, los usuarios solo reciben la información que coincide con sus puntos de vista, aislándose en burbujas de información ideológicas y comunicativas, reafirmándose en sus convicciones sin contrastarlas ni hacer dialogar con otras distintas. Un espejo donde reafirmarnos y una tendencia que se viene consolidando al menos desde 2009, cuando Google anunció la personalización del servicio que ofrecería en adelante a sus usuarios; si antes, al hacer clic en cualquier enlace, el buscador nos devolvía los mismos resultados a distintas personas, desde entonces todo lo que encontremos depende de lo que el buscador ya sepa de nosotros.

En efecto, en los últimos años, las empresas de internet se han obcecado con la personalización y obtención de datos de usuarios, y por ello debiéramos preguntarnos cuánto usamos estas herramientas y cuánto somos usados por ellas. El Big Data se nutre así de los datos del comportamiento humano, de las apps o aplicaciones, de Google Maps, GPS, tarjetas de crédito... de todo aquello que deja huellas digitales en la red. En este contexto de datificación y digitalización de la realidad física, cuando se escriben más de 1.000 millones de comentarios diarios en Facebook y el número de teléfonos móviles ya supera al de habitantes del planeta (RTVE, 2017), toda una serie de tecnologías de la recomendación nos van guiando y siguiendo a través de nuestros gustos y clics, a través de banners y cookies que nutren a portales como LinkedIN o a gigantes como Amazon y Netflix. No olvidemos que no solo nosotros nos conectamos a varios dispositivos, sino que también estos dispositivos se conectan entre sí, compartiendo nuestros datos personales, académicos, laborales, ideológicos, sanitarios, sexuales, etc., que adquieren valor y son el caldo de información del que se alimentan nuevas profesiones como la del data scientist o "científico de datos", que nos recuerdan que a cambio de utilizar un servicio gratuito nuestra privacidad se convierte en moneda y en mercancía; es decir, si no pagamos por el producto... somos el producto.

Ante tal panorama no extraña el auge de las narrativas distópicas, cuyo paradigma contemporáneo podría ser la serie televisiva Black Mirror, dirigida por Charlie Brooker. Un espejo, precisamente, un espejo negro que es el de cada escritorio de ordenador, el de cada palma de la mano, donde una pantalla brillante se enfría; he ahí la alegoría, el reflejo y la imagen oscura de nosotros mismos que nos devuelven las pantallas apagadas (Díaz Gandasegui, 2014). Porque al compás de las cosas brillantes que las nuevas tecnologías nos permiten hacer, la cruz de estos procesos de digitalización de la vida social implica otras cuestiones menos alegres y luminosas, entre ellas la adicción tecnológica. Cada vez más, en todo el mundo, los jóvenes viven (de)pendientes del smartphone en todo momento, siendo lo último que miran y tocan cuando se acuestan y lo primero cuando se levantan, un indicador de identidad personal, presencia y ubicación, que requiere de nosotros que nos actualicemos con cada nueva aplicación o en cada nueva versión (Greenfield, 2017). Un dispositivo que genera adicción en tanto libera un químico en el cerebro (dopamina) que nos hace sentir bien con cada nuevo sonido, con cada luz y vibración, con cada alerta de mensaje; la misma sensación que nos producen los retweets o los likes de Facebook e Instagram.

Figura 3

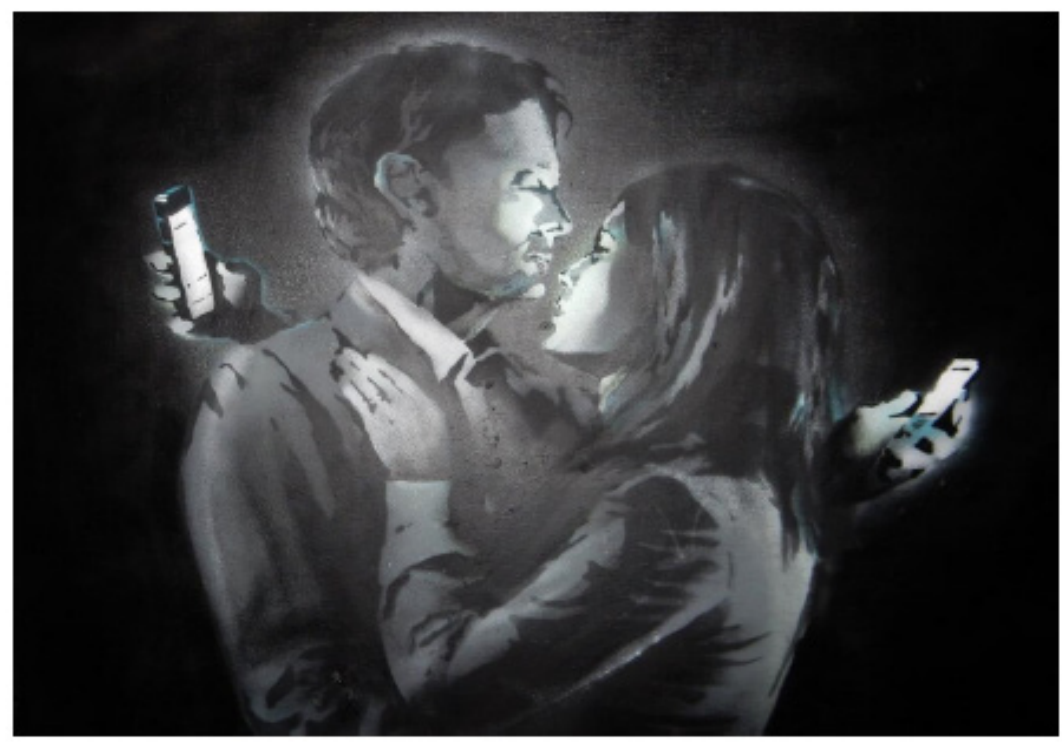

Fuente: Banksy (http://www.banksy.co.uk/). 
Un lado oscuro que ha llevado a catalogar esa dependencia constante por saber de los demás, en redes sociales, como "síndrome FOMO" (Fear Of Missing Out), el miedo a no estar conectados y a perderse algo (Serrano-Puche, 2013). Miedo que corre parejo al de volverse invisibles, a pasar desapercibidos si no cuelgan información con regularidad. Como apunta Winocur, "estar conectado implica esencialmente estar visible. La visibilidad garantiza la inclusión en un mundo cuya representación se ha desplazado de lo palpable a lo comunicable" (citada por Serrano-Puche, 2013: 356). Por supuesto, hay quien resiste a este mundo, quien lo habita de otro modo, quien se desconecta hasta por aburrimiento. Cada vez más, en sociedades post-industriales, la desconexión gana adeptos y el silencio se compra en vagones de tren, resorts, enclaves urbanos, etc. En las redes, hay quien decide "hacer silencio" como un ejercicio activo de discreción, una suerte de huelga de sí mismo, tecnológica y existencial (Le Breton, 2012). Una huelga contra el leitmotiv 24/7, que explica cómo la identidad personal y social se ha reorganizado para ajustarse al ritmo de los mercados y las redes de información, que funcionan 24 horas al día y 7 días a la semana, en una compulsiva economía de la atención que disuelve la frontera entre lo personal y lo profesional, el entretenimiento y la información, etc. (Crary, 2015). Con un talante menos sombrío pero igual de complejo, los recientes movimientos sociales -o movimientos en red (Castells, 2012)- usan y son usados por la red de manera un tanto distinta.

\section{Sincronizando: participación y movimientos sociales en red}

"Ahora nosotros damos las noticias", decía la juventud mexicana en 2012 durante el movimiento \#YoSoy132. Un movimiento que brotó del estudiantado universitario y de su indignación contra el monopolio de los medios de comunicación del país, especialmente Televisa y TV Azteca, alineados con el PRI y las élites económicas. Jóvenes, en su mayoría, nativos digitales o "joveNets", que usaban la red como espacio político, creando opinión y difundiendo mensajes en Twitter, Facebook o YouTube (Candón, 2013). Una situación, la de la concentración de la comunicación por las grandes corporaciones, especialmente visible en América Latina, donde en los últimos años países como Argentina, Ecuador o Venezuela han tratado de aprobar leyes de regulación para ligar la comunicación al interés público e incorporar así a nuevos actores, tradicionalmente privados del acceso a licencias de radio y televisión (Becerra y Mastrini, 2009). Frente a esta lógica empresario-comunicacional de concentración, el uso de la red desafía el viejo "pocos informan a muchos" en favor del "muchos informan a muchos" (Córdula Almeida, Barbosa de Souza, y Bispo dos Santos, 2015), rompiendo con el monopolio de la enunciación y del poder de decir (Lévy, 2004).

Históricamente, los movimientos sociales han tenido que generar sus propios mecanismos de comunicación, ya fuesen carteles, eslóganes, rumores, manifiestos, panfletos, octavillas, sermones, etc. Hoy, las tecnologías digitales permiten que su producción y distribución sean globales, colaborativas, menos costosas y relativamente más seguras. Es decir, la historia de los movimientos sociales -también la del ciberactivismo- es "la historia de la apropiación de los mecanismos e instrumentos para contar y difundir informaciones" (Tascón y Quintana, 2012: 102). En este caso, los recientes movimientos en red se ven atravesados por dos procesos simultáneos: uno es el de la paulatina (e irregular) democratización tecnológica, con más gente pudiendo acceder a más herramientas y canales; y otro es el de la progresiva crisis y pérdida de legitimidad de las élites de la comunicación, sujetas al rechazo y a la desconfianza por sus vínculos con el poder, la política y el mercado. En este contexto, internet y las redes sociales se convierten para los jóvenes -aunque también sean usadas, cada vez más, como "redes políticas" por los partidos, especialmente durante las campañas electorales (Baggiolini y Castro Rojas, 2016)- en el medio de comunicación más popular, rápido, autónomo e interactivo, a la vez que ponen de manifiesto que las características de los procesos de comunicación inciden en las características organizativas del movimiento social: "cuanto más interactiva y autoconfigurable sea la comunicación, menos jerárquica es la organización y más participativo el movimiento" (Castells, 2012: 32).

En España, cuando el 15M se echó a las calles y ocupó las plazas durante semanas en 2011, protestando contra la crisis financiera y exigiendo democracia "real", "directa" y "participativa" -con todos sus problemas y con todas sus contradicciones-, los jóvenes tradujeron a la ciudad una lógica comunicacional y una cultura participativa propia de la red, que es donde se había desarrollado las discusiones previas, los preparativos y la convocatoria final. En carteles o pancartas, durante las acampadas, el $15 \mathrm{M}$ usó irónicamente lemas con un lenguaje metafórico, informático y computacional, típico del ciberespacio y del mundo digital: "ERROR 404: Democracy Not Found", "Error de sistema. Reinicie, por favor". La conexión propia de la red se llevó al plano urbano a través de acampadas y movilizaciones descentralizadas, simultáneas, más o menos horizontales e interrelacionadas, y no exentas de organización (aunque fuera líquida) ni de liderazgos (aunque fueran débiles), pues las personas con más influencia en las redes sociales asumían en cierto modo el rol de coreógrafos, sugiriendo formas y gestos que se harían visibles en las calles (Gerbaudo, 2012). Porque, al fin y al cabo, "en la cultura de la convergencia, todos son participantes, aunque con dife- 
rentes estatus y grados de influencia" (Jenkins, 2008: 138). Una cultura de la convergencia donde chocan y se yuxtaponen los viejos y los nuevos medios, los viejos y los nuevos paradigmas de la comunicación, y donde cada cambio mediático es mucho más que un cambio tecnológico, pues afecta enteramente nuestras relaciones, culturas e identidades.

En el ciberespacio, antes, durante y después de la acción en las calles, los jóvenes expandían en internet sus movimientos a partir de un intercambio ingente de mensajes [Figura 4]. Creaban un registro imparable, una conversación continua, a menudo abrumadora e inabarcable, y lo hacían de manera colectiva, instantánea y efímera, igual que en los primerizos chats del IRC (Mayans i Planells, 2002). Y también fragmentariamente, combinando distintas posibilidades literarias que iban de la recuperación de la escritura telegráfica (SMS, WhatsApp) a los microrrelatos de Twitter, facilitado por la maleabilidad y manipulación textual que alientan las nuevas textualidades digitalizadas (Scolari, 2012, 2012b). Porque el texto digital contemporáneo, fluido, confuso, metamórfico, dinámico, anti-lineal, polifónico, desterritorializado y sin fronteras claras, recrea y reconstituye virtualmente la comunicación oral (Lévy, 1999); una conversación hipertextual abierta y nunca acabada del todo, donde todo es efímero y a la vez todo queda registrado, y donde "el hipertexto nos reencuentra con la más antigua textualidad, la del palimpsesto cuya escritura se hacía con un punzón sobre una tablilla de cera que se usaba mil veces escribiendo sobre la borradura de lo ya escrito" (Martín-Barbero, 2015: 16). He ahí cómo lo "nuevo" encuentra lo "viejo", y cómo cualquier conversación -en la calle o en Facebook- guarda siempre un carácter dialógico, creativo, heteroglósico, intersubjetivo e intertextual, pues el habla es una acción social y coral, y toda comunicación, todo texto y todo lenguaje operan y se producen en contexto (Bourdieu, 1985; Duranti, 2000; Bajtín, 2004).

Figura 4. Muestra geoposicionada de mensajes entre participantes del 15M

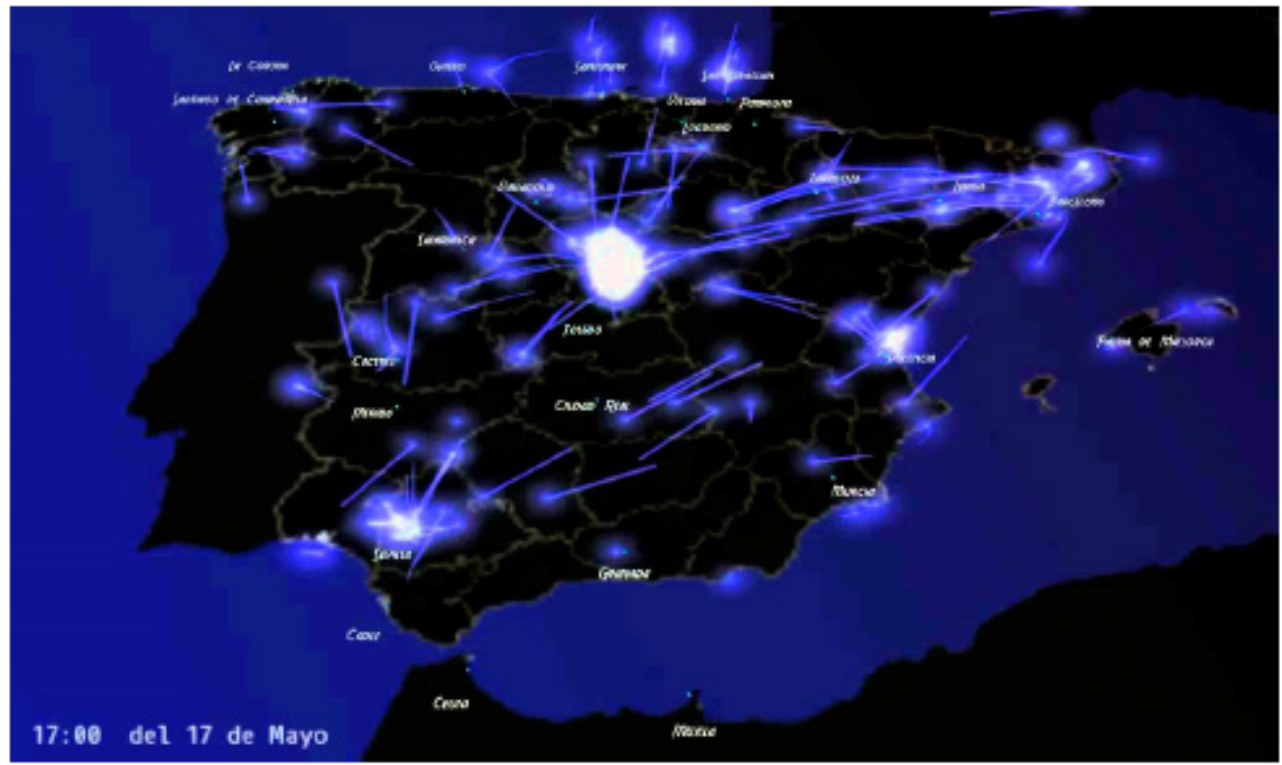

Fuente: BIFI (http://15m.bifi.es/index.php).

Si bien podemos aceptar, entendiendo que la cultura abarca "el conjunto de los procesos sociales de producción, circulación y consumo de la significación en la vida social" (García Canclini, 1997: 35), que la multiplicación de recursos tecnológicos convierte los hechos sociales en acontecimientos espectaculares, a la vez podemos señalar la oportunidad que ofrecen las nuevas redes para romper el carácter pasivo asociado al espectador y a las audiencias juveniles. Existe un riesgo, en efecto: que los contenidos y narraciones de estas redes se conviertan también en espectáculo, pero el "contraconsumo" de información que hacen estos jóvenes respecto a los mass media tradicionales los lleva a practicar sistemáticamente una producción activa y relacional de contenidos, lo cual nos recuerda que el consumo lleva implícito una actividad de manipulación de signos y de sustancia significante (Baudrillard, 2012), cuya circulación constituye hoy un lenguaje fundamental para las vidas digitales de estos jóvenes conectados. Por ello coincidimos con Serrano-Puche (2013) cuando califica de "reduccionista" la visión de las tecnologías digitales como tecnologías de la información y la comunicación (TICs); en realidad, la reapropiación que de ellas han hecho estos recientes movimientos sociales las convierten también en tecnologías del aprendizaje y del conocimiento, en tecnologías para el empoderamiento y la participación. Bien sea en las plazas, con el cuerpo expuesto 
públicamente pero con los dedos pegados al smartphone (Diz, 2013); o bien desde la habitación de una "casa mediatizada" -que es el prototipo del ámbito privado contemporáneo, donde puedes conectarte con lugares distantes (Morley, 2008)-, estos jóvenes -muchos "hiperformados" e "hiperinformados" (Feixa y Nofre, 2013)- comunicaban, aprendían, participaban y reconstruían directamente los marcos del discurso y de la realidad.

En Túnez y Egipto, donde se inició en 2010 la "primavera árabe", se hizo patente esta "autocomunicación de masas" en la que el emisor decidía los mensajes de manera autónoma, designaba a sus posibles receptores y seleccionaba la información que quería difundir, difícil de controlar por el gobierno (Castells, 2012). En Túnez, los ciberactivistas hallaron un aliado en la televisión por satélite alejada del control gubernamental, en especial Al Jazeera, que llegó a desarrollar un programa de comunicación que permitía conectar entre sí el satélite y los móviles de los activistas, reconvertidos en una suerte de periodistas freelance. En Egipto, el régimen de Mubarak intentó apagar la conexión a internet y a las redes de telefonía en todo el país, topándose con el obstáculo de una activa comunidad global digital, poblada por hackers, plataformas multimodales, redes como Anonymous y defensores de las libertades civiles que ven en internet un derecho y una forma de vida, y que respondieron rápidamente para mantener la comunicación y la protesta on line (Coleman, 2016)

En estos casos, como indica Castells (2012), el espacio público de los movimientos en red se construía como un espacio híbrido, a caballo entre las redes sociales de internet y el espacio urbano ocupado por las acampadas. Es como si el entramado de perfiles, alias y emoticonos, como si el juego virtual de tecnopresencias supiese que hacía falta, finalmente, juntar los cuerpos en las calles para hacerse más fuertes, reconocibles y visibles. En este sentido, las vidas digitales de estos jóvenes pasaban en última instancia por encontrarse ahí fuera, por combinar pantalla y asfalto, conversación en línea y charla en la plaza. Es justamente esta sincronización multi-escala la que tenía lugar entre el mundo on line y el urbano, pero también entre distintos ordenadores y direcciones IP, territorios locales y nacionales, jóvenes y máquinas, jóvenes y movimientos sociales, y finalmente una sincronización entre movimientos y países.

Todas estas interacciones, réplicas e intercambios, que algunos -optimistas- han analizado a través de su carácter viral y contagioso, con un lenguaje pandémico y epidemiológico (Postill, 2014), darían el salto de las revueltas norteafricanas a Europa, y de allí al continente americano. La convocatoria del 15 de octubre de 2011, impulsada por el 15M en redes sociales y bajo el lema United for Global Change, reunió a millones de personas en las calles de Madrid, Londres, Nueva York, Santiago de Chile o Bogotá, fomentando el surgimiento de plataformas virtuales como MxTomaLacalle.org -vinculada posteriormente al movimiento mexicano \#YoSoy132, de 2012- o los nodos brasileños de OccupaSampa (São Paulo) y Democracia Real Já, activos durante el movimiento Passe Livre de 2013. Sincronizaciones que eran producto de una expansión comunicativa y de una cultura colaborativa caracterizada por el remix, el contagio y la remezcla constante (Lessig, 2012) Una cultura de la participación que brota en internet y se expande hacia fuera, y que sabe que en la web la política se redimensiona hasta el punto de confundirse las fronteras entre comunicación y participación.

\section{Cerrando sesión: conclusiones}

Cerramos este artículo tal y como lo abrimos, circulando y haciendo navegar el texto por internet, entre el sur de Europa y el África oriental, añadiendo comentarios y sucesivas correcciones. Lo hacemos viajar en el tiempo y en el espacio, sabiendo que con cada nuevo envío dejamos un rastro digital de nosotros colgando en alguna parte, o anclado a alguna nube. Nos sabemos (o nos creemos) aún jóvenes, pero sobre todo sabemos -a veces a nuestro pesar- que también nuestras vidas son vidas digitales, o mejor, vidas en permanente proceso de digitalización.

Las vidas digitales de las que hemos hablado, las de los jóvenes conectados a internet que se sirven de las nuevas tecnologías para participar en discusiones y acciones públicas y que politizan tales herramientas para contestar o repensar el mundo, son vidas digitalizadas (y digitalizables) en tanto en cuanto están expuestas a un proceso global y tecnológico de digitalización del mundo social, el cual comporta una redefinición permanente de la realidad y la consiguiente mutación de la identidad de estos jóvenes, abocados a contextos híbridos de relación y aprendizaje. Las vidas digitales, por lo tanto, no son vidas cerradas sino en constante conexión, actualización y sincronización; son vidas que se viven en tanto se digitalizan, y son vidas que se digitalizan en tanto son vividas socialmente, en una constante conexión e interacción.

Hemos seguido sus procesos de conexión, analizando las metáforas con las que hablan, los nervios que los recorren y las brechas inherentes al proceso de digitalización. Hemos atendido a sus sucesivas actualizaciones, analizando la cara más luminosa y la más sombría de la comunicación y las tecnologías en la era de la información. Por último, hemos comentado algunas de las formas de participación más recientes, analizando la relación entre la red y los movimientos sociales contemporáneos, y atendiendo a sus procesos 
de contagio y sincronización, de lo local a lo global. Al hacerlo, hemos comprobado que, en gran medida, el activismo ya no solo se sirve de la red sino que incorpora su arquitectura e hipertextualidad a su definición y a su repertorio de acción; no solo se sirve de la red sino que es una red. Y también hemos comprobado la firme interconexión y reciprocidad entre lo digital y lo urbano, descubriendo una cultura de la participación en red que, a menudo, es el reflejo de una cultura de la participación en la red.

Son estas, en fin, vidas digitales que hacen de la comunicación su razón de ser primordial, un campo de relación e identidad pero también un campo de batalla político, simbólico y económico. Vidas digitales que abren y producen nuevos lenguajes, nuevos relatos, nuevos códigos, nuevos espacios, nuevas cronologías, nuevas velocidades y nuevos repertorios de acción social. Son, en definitiva, vidas enredadas, entre la piel y el salvapantallas.

\section{Bibliografía}

Appadurai, A. (Ed.). (2002). Globalization. Durham: Duke University Press.

Baggiolini, L., y Castro Rojas, S. (2016). "Las redes de la política: universo narrativo, campañas y microrrelato en twitter", InMediaciones de la Comunicación, (11), 159-180.

Bajtín, M. (2004). The Dialogic Imagination. Austin: University of Texas Press.

Baudrillard, J. (2012). La sociedad de consumo. Madrid: Siglo XXI.

Becerra, M., y Mastrini, G. (2009). Los dueños de la palabra: acceso, estructura y concentración de los medios en la América Latina del siglo XXI. Buenos Aires: Prometeo.

Bourdieu, P. (1985). ¿Qué significa hablar? Economía de los intercambios lingüísticos. Madrid: Akal.

Candón, J. (2013). "Movimientos por la democratización de la comunicación: los casos del 15-M y \#Yosoy132", Razón y Palabra, 18(87), 370-386.

Castells, M. (2003). La era de la información. Madrid: Alianza.

Castells, M. (2012). Redes de indignación y esperanza: los movimientos sociales en la era de internet. Madrid: Alianza.

Coleman, G. (2016). Las mil caras de Anonymous. Hackers, activistas, espías y bromistas. Barcelona: Arpa.

Córdula Almeida, V., Barbosa de Souza, T., y Bispo dos Santos, V. (2015). "Internet y redes sociales: ¿artefacto tecnológico o locus digital para la movilización política?", Chasqui. Revista Latinoamericana de Comunicación, (128), 85-99.

Crary, J. (2015). 24/7. El capitalismo al asalto del sueño. Barcelona: Planeta.

Díaz Gandasegui, V. (2014). "Black Mirror: el reflejo oscuro de la sociedad de la información”, TecknoKultura, 11(3), 583-606.

Diz, C. (2013). Políticas del cuerpo y heterotopías del\# 15M. Revista de antropología experimental, (13), 89-111.

Diz, C. (2016). "Escuelas de democracia y 15M: participación, redes, ensayos", Educação em Perspectiva, $7(2), 367-390$.

Diz, C. (2016a). Objetos tirados, objetos sagrados. Reapropiación tecnológica de la bicicleta, Revista de Antropología Experimental (16), 147-165. DOI: http://dx.doi.org/10.17561/rae.v0i16.3022.

Diz, C. (2016b). Políticas y tácticas del cuerpo: Retablos de la ciudad activista (Tesis doctoral). Universidade da Coruña, A Coruña. Recuperado de: http://ruc.udc.es/dspace/handle/2183/16405.

Duranti, A. (2000). Antropología lingüística. Madrid: Cambridge University Press.

Estalella, A. (2012). "Ensamblajes de esperanza", Athenea Digital, 12(2), 161-174.

Feixa, C. (2014). De la Generación@ a la \#Generación: la juventud en la era digital. Barcelona: Ned Ediciones.

Feixa, C., y Nofre, J. (Eds.). (2013). \#Generación indignada: topías y utopía del 15M. Lleida: Milenio.

García Canclini, N. (1997). Cultura y comunicación: entre lo global y lo local. La Plata: Ediciones de Periodismo y Comunicación.

García Huerta, D. (2014). "Las imágenes macro y los memes de internet: posibilidades de estudio desde las teorías de la comunicación", Paakat, 4(6).

Gerbaudo, P. (2012). Tweets and the Streets: Social Media and Contemporary Activism. London: Pluto Press.

Goffman, E. (1987). La presentación de la persona en la vida cotidiana. Buenos Aires: Amorrortu.

Greenfield, A. (2017). Radical Technologies. The Design of Everyday Life. London: Verso. 
Jenkins, H. (2008). Convergence Culture. Barcelona: Paidós.

Jurado Gilabert, F. (2014). Nueva gramática política. De la revolución en las comunicaciones al cambio de paradigma. Barcelona: Icaria.

Juris, J. S. (2008). Networking Futures. The movements against corporate globalization. Durham: Duke University Press.

Klein, N. (2001). NO LOGO. El poder de las marcas. Barcelona: Paidós.

Lakoff, G., y Johnson, M. (1998). Metáforas de la vida cotidiana. Madrid: Cátedra.

Lessig, L. (2012). Remix. Cultura de la remezcla y derechos de autor en el entorno digital. Barcelona: Icaria.

Lévy, P. (1999). ¿Qué es lo virtual? Barcelona: Paidós.

Lévy, P. (2004). Ciberdemocracia. Barcelona: UOC.

Le Breton, D. (2012). El silencio. Barcelona: SEQUITUR.

Martín-Barbero, J. (2015). “¿Desde dónde pensamos la comunicación hoy?”, Chasqui. Revista Latinoamericana de Comunicación, (128), 13-29.

Martínez Rolán, X., y Piñeiro-Otero, T. (2017). "El uso de los memes en la conversación política 2.0", Prisma Social, (18), 55-84.

Mayans i Planells, J. (2002). Género chat, o cómo la etnografía puso un pie en el ciberespacio. Barcelona: Gedisa.

McLuhan, M. (2010). A Galaxia Gutenberg. Santiago de Compostela: USC.

Morley, D. (2008). Medios, modernidad y tecnología. Barcelona: Gedisa.

Pariser, E. (2017). El filtro burbuja: cómo la web decide lo que leemos y lo que pensamos. Madrid: Taurus.

Piscitelli, A. (2009). "Facebook. Esa reiterada tensión entre la sobrepromesa y la invención de nuevos mundos", Revista de Universidad y Sociedad del Conocimiento, 6(1), 43-52.

Postill, J. (2014). "Democracy in an Age of Viral Reality: A Media Epidemiography of Spain's Indignados Movement", Ethnography, 15(1), 51-69.

Postman, N. (1994). Tecnópolis: la rendición de la cultura a la tecnología. Barcelona: Galaxia Gutenberg.

RTVE (productora), Soto Romero, M., y Arranz, M. (directores). (2017). Big Data, conviviendo con el algoritmo [documental]. España: TVE.

Scolari, C. (2012a). "Comunicación digital: Recuerdos del futuro", El profesional de la información, 21(4), $337-340$.

Scolari, C. (2012b). "Marshall McLuhan: ¿Un Nostradamus del siglo XX?”, La Trama de la Comunicación, (16), 13-18.

Sennett, R. (1997). Carne y piedra. Madrid: Alianza.

Serrano-Puche, J. (2013). "Vidas conectadas: tecnología digital, interacción social e identidad", Historia y Comunicación Social, (18), 353-364.

Simmel, G. (2002). Sobre la individualidad y las formas sociales. Buenos Aires: Universidad de Quilmes. Slouka, M. (1996). War Of The Worlds. New York: Harper Collins.

Tascón, M., y Quintana, Y. (2012). Ciberactivismo. Madrid: Catarata.

Thompson, E.P. (1974). Tradición, revuelta y consciencia de clase. Barcelona: Crítica.

Urry, J. (2007). Mobilities. Malden, Massachussetts: Polity Press.

Virilio, P. (1997). Un paisaje de acontecimientos. Barcelona: Paidós.

Warnier, J-P. (2002). La mundialización de la cultura. Barcelona: Gedisa. 